\title{
BMJ Open World Café approach: exploring the future vision of oral anticoagulants for patients with atrial fibrillation (AF) in Ireland
}

\author{
Aileen Murphy (D) , ${ }^{1}$ Stephen Brosnan, ${ }^{1}$ Stephen McCarthy, ${ }^{2}$ Paidi O’Raghallaigh, ${ }^{3,4}$ \\ Colin Bradley, ${ }^{5}$ Ann Kirby (D) ${ }^{1}$
}

To cite: Murphy A, Brosnan S, McCarthy S, et al. World Café approach: exploring the future vision of oral anticoagulants for patients with atrial fibrillation (AF) in Ireland. BMJ Open 2020;10:e036493. doi:10.1136/ bmjopen-2019-036493

- Prepublication history and additional material for this paper is available online. To view these files, please visit the journal online (http://dx.doi.org/10. 1136/bmjopen-2019-036493).

Received 17 December 2019 Revised 08 June 2020 Accepted 20 August 2020

\section{Check for updates}

(c) Author(s) (or their employer(s)) 2020. Re-use permitted under CC BY-NC. No commercial re-use. See rights and permissions. Published by BMJ.

${ }^{1}$ Department of Economics, Cork University Business School, University College Cork, Cork, Ireland

${ }^{2}$ Department of Business Information Systems, Cork University Business School, University College Cork, Cork, Ireland

${ }^{3}$ INFANT Research Centre, University College Cork, Cork, Ireland

${ }^{4}$ Cork University Business School, University College London, London, UK

${ }^{5}$ Department of General Practice, University College Cork, Cork, Ireland

Correspondence to

Dr Aileen Murphy;

aileen.murphy@ucc.ie

\section{ABSTRACT}

Objectives To explore and reflect on the current anticoagulation therapy offered to patients with atrial fibrillation (AF), potential challenges and the future vision for oral anticoagulants for patients with $\mathrm{AF}$ and healthcare professionals in Ireland.

Design A multistakeholder focus group using a World Café approach.

Participants Nine participants from academic, clinical and health backgrounds attended the focus group together with a facilitator.

Results Enhanced patient empowerment; more effective use of technology and developing system-based medical care pathways would provide improved supports for AF management. The challenges in providing these include cost and access issues, the doctor-patient relationship and the provision of education. While consensus for developing evidence-based pathways to maximise efficiency and effectiveness of $\mathrm{AF}$ treatment was evident, it would require a shared vision between stakeholders of integrated care. The benefits of embracing technological advances for clinicians and patients were evident; however, clinicians indicate this can increase pressure on already stretched resources; coupled with institutional barriers (including scarce resources) arising from the complex nature of anticoagulation for patients with $\mathrm{AF}$, which emerged strongly. Including the unpredictable nature of warfarin, hidden costs associated with monitoring, adverse clinical effects, different patient cohorts (including those prescribed anticoagulant for the first time vs those switching from warfarin to a new oral anticoagulant (NOAC)), non-adherence concerns and undesirable impacts on patients' daily lives.

Conclusions While anticoagulation therapy for patients with AF using NOACs has been widely adopted and is diffusing into routine practice, significant operationalisation issues and barriers to effective treatment/management persist. The reflections reported in this study are a catalyst for future discussion and research.

\section{INTRODUCTION}

Long-term oral anticoagulation therapy is routinely used to reduce risk of atrial fibrillation (AF)-related stroke and can prevent approximately two-thirds of AF-related
Strengths and limitations of this study

- This study reflects on key challenges facing patients with atrial fibrillation (AF) and the healthcare professionals prescribing and managing their treatment using qualitative evidence collected via a multistakeholder focus group.

- This is the first study that explores the current situation and future vision for anticoagulation and new oral anticoagulants for AF in Ireland using a qualitative approach.

- Overarching themes were supporting AF management and potential barriers to effective treatment.

- Owing to low uptake on consultation invitations participants were from a similar geographical area.

- The reflections reported in this study are a catalyst for future discussion and research.

strokes. ${ }^{12}$ Until recently warfarin was the go-to oral anticoagulation therapy. However, with the emergence of the new oral anticoagulants (NOACs) (also referred to as direct oral anticoagulants) additional choices are now available. These NOACs have revolutionised the treatment of $\mathrm{AF}^{3-6}$ and are expected to reduce underprescribing and high discontinuation rates traditionally associated with oral anticoagulation therapy. ${ }^{78}$ While NOACs have been on the market for some years, their adoption has been slower in some jurisdictions like Ireland; where warfarin was until recently the 'preferred drug' recommended by the national Medicines Management Programme. ${ }^{9}$ Latterly, apixaban has been declared as the preferred NOAC that can be used as first-line treatment if a patient has tolerability or other issues with warfarin. ${ }^{9}$ Nevertheless, NOACs are increasingly being prescribed $^{10}$ and adopted into routine practice. For example, between January 2013 and August 2015, there was a 4.5-fold increase in the number of patients on NOACs. 
Expenditure on NOACs increased sixfold between 2014 and $2017,{ }^{11}$ while expenditure on warfarin in the same period decreased by approximately a third. ${ }^{10} 12$ This diffusion and adoption of new drugs is an important element in the innovation process. While prescribing guidelines for oral anticoagulants for stroke prevention in non-valvular $\mathrm{AF}$ are available there is currently no National Clinical Guideline for managing patients with AF prescribed oral anticoagulants for stroke prevention.

Warfarin is a difficult drug to use safely due to the tendency to cause interactions with other medicines and its narrow therapeutic range ${ }^{13}$ leading to increased risk of bleeding while on treatment; necessitating international normalised ratio (INR) monitoring (a test measuring how long it takes the blood to clot), which is costly for patients and providers. ${ }^{14}$ NOACs offer a number of advantages, most particularly obviating the requirements for INR-level monitoring necessary with warfarin therapy. However, there are caveats and cautions owing to their side effects. ${ }^{15}$ Monitoring of renal and liver function as well as for unexpected bleeding episodes or thrombosis; compliance to therapy; and drug interactions is recommended. ${ }^{16}$ While the American College of Cardiology, American Heart Association and European Society of Cardiology have developed and recommended clinical practice guidelines on use of NOACs, ${ }^{17-19}$ recent research in Ireland ${ }^{20-23}$ and elsewhere ${ }^{2425}$ suggests suboptimal adherence to such guidelines and mixed experiences and views among clinicians managing patients with AF prescribed NOACs. In the case of Ireland, a survey of general practitioners (GP) identified lack of integration between primary and secondary care and knowledge gaps among prescribers with regard to prescribing decision-making and managing patients with $\mathrm{AF}$ prescribed NOACs (in the absence of INR monitoring requirements) ${ }^{20-22}$

While there is an abundance of evidence from systematic trials and meta-analysis on the efficacy and effectiveness of safety of oral anticoagulation therapy in the management of AF, there is limited qualitative evidence capturing both the clinicians ${ }^{25}$ and patients' views $^{6}$ simultaneously. Generating qualitative evidence provides the opportunity to add depth and ensuring focus on patient-level care. ${ }^{26}$ This study contributes to this gap, employing participatory methods to explore the current situation and future vision for managing patients with $\mathrm{AF}$ with oral anticoagulants from multiple perspectives. Now is an important time to influence how NOACs are diffused and adopted to inform National Clinical Guideline development, before diffusion is widespread. This paper is a reflection on current anticoagulation therapy offered to patients with $\mathrm{AF}$, with some key challenges facing patients with $\mathrm{AF}$ and healthcare professionals prescribing and managing $\mathrm{AF}$ treatment identified, using a World Café methodology via a multistakeholder focus group.

\section{METHOD}

A multistakeholder focus group took place on the $12^{\text {th }}$ April 2019, between 11:00 and 16:00 in a private function room on the university main campus. The focus group was organised by the authors as part of ongoing research on anticoagulants involving academics from the Department of Economics and the Department of General Practice in an Irish university. The focus group centred on the future of AF management in the era of NOACs. The World Café ${ }^{27}$ method, a conversational process permitting productive discussion around critical questions, was chosen to facilitate face-to-face dialogue between participants. Participants were seated at a round table and invited to discuss the theme 'Anticoagulants the changing environment-the future of Atrial Fibrillation management in the era of NOACs' during dedicated breakout and plenary sessions. There were four rounds arranged as follows: (1) a back-casting exercise encouraging participants to picture the future of anticoagulation; (2) metrics for achieving the future outlined in (1); (3) removing barriers; and (4) key deliverables. Online supplemental table 1 provides an overview of the scheduled programme of the focus group and the four discussion rounds.

A convenience sampling method was adopted for this study. Participants were invited by email to attend the focus group and a skilled facilitator was employed to structure the focus group, ask prompting questions and provide each participant with an equal chance to contribute their opinion. Participants were purposefully selected to ensure diverse representation of different stakeholders (i.e., profession (doctor, nurse, pharmacist, and so on), working environment (primary and secondary care)). Two dedicated scribes were present to record the views and personal experiences of participants with their permission. The results are presented in line with the Standards for Reporting Qualitative Research (SRQR). ${ }^{28}$

\section{Patient and public involvement}

Several patient advisory groups were contacted to attend the multistakeholder focus group, only one group responded positively and a patient contributor attended and participated in the focus group. Prior to publication the patient representative reviewed the findings and gave permission for their comments to be included in the dissemination.

\section{Data analysis}

Qualitative thematic analysis employing the six-step framework (Braun and Clarke ${ }^{29}$ ) was used to identify themes. The thematic analysis provides a flexible approach for analysing qualitative data. The adopted six-step framework ${ }^{29}$ approach offers a less linear, rigid process whereby an iterative approach is adopted to reveal further key themes or issues, as presented in table 1. Coding is presented in online supplemental tables 2-4.

\section{RESULTS}

Nine participants accepted the email invitation to attend the focus group, a 32\% response rate. See online 
Table 1 Phases of thematic analysis

\begin{tabular}{|c|c|c|}
\hline Phase & Description of process & Steps taken \\
\hline $\begin{array}{l}\text { 1. Familiarising } \\
\text { yourself with } \\
\text { your data }\end{array}$ & $\begin{array}{l}\text { Transcribing data (if necessary), reading and re- } \\
\text { reading the data, noting down initial ideas. }\end{array}$ & $\begin{array}{l}\text { Two co-authors (SB and SMC) had already taken notes } \\
\text { during the focus group and had thus already been exposed } \\
\text { to the data. Following the conclusion of the focus group, } \\
\text { each note taker scribed their notes separately. This provided } \\
\text { two separate transcripts of the focus group. }\end{array}$ \\
\hline $\begin{array}{l}\text { 2. Generating } \\
\text { initial codes }\end{array}$ & $\begin{array}{l}\text { Coding interesting features of the data in a systematic } \\
\text { fashion across the entire data set, collating data } \\
\text { relevant to each code. }\end{array}$ & $\begin{array}{l}\text { In total, three rounds of coding were conducted in order } \\
\text { to iteratively make sense of themes emerging from the } \\
\text { data. During the first round, two co-authors (SB and } \\
\text { SMC) developed coding frames of the transcriptions } \\
\text { independently using NVivo V.12. The use of a } \\
\text { multidisciplinary coding team helped to address potential } \\
\text { concerns regarding researcher influence on the nature of } \\
\text { analysis. }{ }^{45}\end{array}$ \\
\hline $\begin{array}{l}\text { 3. Searching for } \\
\text { themes }\end{array}$ & $\begin{array}{l}\text { Collating codes into potential themes, gathering all } \\
\text { data relevant to each potential theme. }\end{array}$ & $\begin{array}{l}\text { Following initial coding, the two coders (SB and SMC) } \\
\text { separately identified potential themes and subthemes within } \\
\text { the transcript of the focus group discussion. }\end{array}$ \\
\hline $\begin{array}{l}\text { 5. Defining and } \\
\text { naming themes }\end{array}$ & $\begin{array}{l}\text { Ongoing analysis to refine the specifics of each theme, } \\
\text { and the overall story the analysis tells, generating } \\
\text { clear definitions and names for each theme. }\end{array}$ & $\begin{array}{l}\text { The third and final round of coding involved two other co- } \\
\text { authors (AM and AK) independently reviewing the themes } \\
\text { that emerged from the second round of coding. }\end{array}$ \\
\hline $\begin{array}{l}\text { 6. Producing the } \\
\text { report }\end{array}$ & $\begin{array}{l}\text { The final opportunity for analysis. Selection of vivid, } \\
\text { compelling extract examples, final analysis of selected } \\
\text { extracts, relating the analysis back to the research } \\
\text { question and literature, producing a scholarly report of } \\
\text { the analysis. }\end{array}$ & $\begin{array}{l}\text { Lastly, all coauthors contributed towards the production of } \\
\text { the report which was guided by the previous five steps of } \\
\text { thematic analysis. }\end{array}$ \\
\hline
\end{tabular}

Source: Authors own, based on Braun and Clarke (29, p 87). Codes generated are presented in online supplemental tables $2-4$.

supplemental table 5 for participant's details. The narrative, grounded in the experiences of stakeholders, highlights a number of contextual factors that influence the future direction of anticoagulant treatment for patients with AF in Ireland. By identifying and classifying individual themes, this section assists in categorising key practical, managerial and strategic issues which are likely to influence future opportunities and challenges in treatment of patients with AF in Ireland. The two overarching themes are: (1) supporting AF management and (2) the potential barriers to effective treatment. Furthermore, six subthemes were identified from the transcripts relating to patient empowerment, system-based medical care pathways, technologies, anticoagulant issues, switching to NOACs and barriers to effective treatment (figure 1). These themes illustrate future opportunities and challenges facing academics, policymakers, health practitioners and patients in the design and implementation of systems of AF treatment. Online supplemental table 6 presents the completed SRQR. ${ }^{28}$

\section{Theme 1. Supporting AF management}

Patient empowerment

The cost and access to medical treatment were identified as key barriers to empowering patients with AF in Ireland. Participants highlighted the importance of taking into account the full cost of AF treatment including travel, parking and time-off work for patients and accompanying family members.

Doctor-patient communication plays a central role in developing effective doctor-patient relationships. ${ }^{30}$ Both academics and patients identified a breakdown in doctorpatient communication as a potential barrier to patient

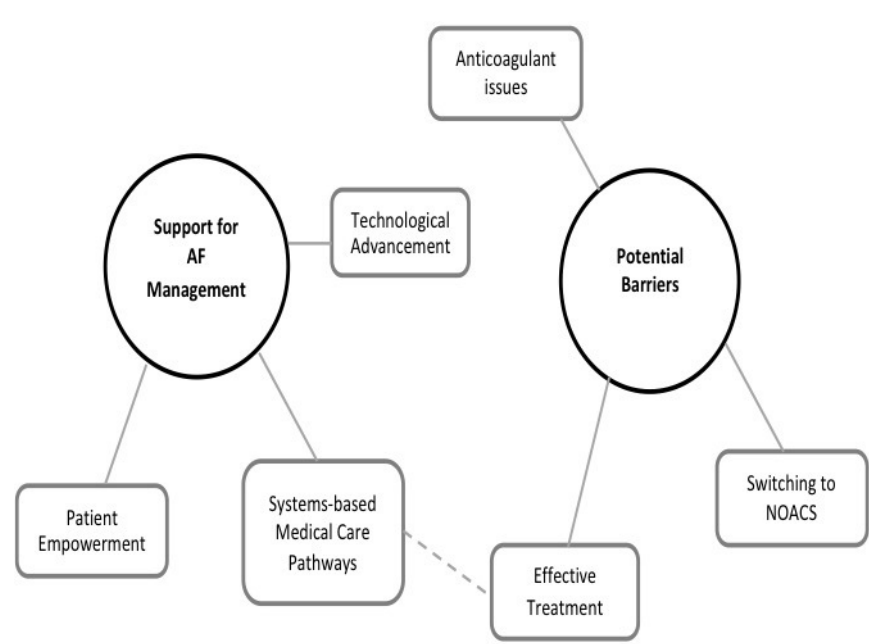

Figure 1 Thematic map of future of atrial fibrillation (AF) management. NOACs, new oral anticoagulants. 
Table 2 Supporting AF management

\begin{tabular}{lll}
\hline Theme & Subtheme & Reflection \\
\hline $\begin{array}{l}\text { Supporting AF } \\
\text { management }\end{array}$ & empowerment & The access and cost of medical \\
& & treatment is a key barrier to patient \\
empowerment.
\end{tabular}

Exemplary quote

'In Scotland, I could buy my strips in a local pharmacy. empowerment.

Doctor-patient communication plays a central role in patient empowerment.

Education and health literacy are the biggest barriers to patient empowerment.

System-based Need to develop a shared vision medical care for an integrated care pathway for pathways AF treatment.

There are a variety of healthcare professionals (primary doctor, pharmacist, nurse) who could provide education and follow-up.

Preventative health measures should be emphasised as opposed to reactionary health measures.

Data-driven environment required to maximise the efficiency and effectiveness of AF treatment.

Technological Clinician IT empowerment will advancement contribute to increased diagnosis and more efficient decisionmaking.

Patient IT empowerment will contribute to increases in effectiveness and efficiency of diagnosis.
Here I have to be chasing delivery vans for two days at a time because they won't leave them at my house [if I am not there] because it is a medical delivery. I have to order them three weeks in advance and pay €117 and €20 delivery.'

'The biggest fear is asking your doctor or specialist about your condition. Irish people have a habit of not reviewing their medication. They don't question it and they should. You need to be as informed as possible in order to review your medication.'

'The biggest barrier is medical education. There is also the issue of the medicine management.'

'Can we get an integrated care pathway? We need to get the HSE on board and involve stakeholders at a national level.'

'They could move this out of the hospital and into the community. Patients don't need the same level of access to the hospital.'

'Currently, $10 \%$ of over 65 s have an AF screening. The vision would be for at least $75 \%$ of over 65 to have a screening.'

'Practical guidelines, information sharing to keep everyone involved, unique identifiers so that patients do not need to repeatedly tell their story starting from scratch.'

'There will likely be an explosion in diagnosis coming with new decision support tools that will be available in the future.'

'Patients [using personal devices] get a mobile reading about an acute episode and figure out a way forward. They can get a rapid diagnosis by themselves within 24 hours.'

AF, atrial fibrillation; HSE, health services executive; IT, information technology.

empowerment. Multiple reasons have been suggested as the causes of this miscommunication. Participants identified fear and anxiety among both clinicians and patients as potential barriers. Participants point to instances where the patient knowingly provides incorrect information or takes actions that distort test results. This can contribute to a lack of trust in the doctor-patient relationship, with increased fear of litigation on the part of the clinician. This can have a significant impact on the AF treatment process and health outcomes.

The importance of health literacy was highlighted as a key factor in improving doctor-patient communication and enhancing patient empowerment among participants. They proposed that improvements in patient education and health literacy will contribute to improvements in both patient confidence and doctor-patient communications (see table 2).
System-based approach to medical care pathways

There was a general consensus among participants that an integrated medical care pathway was required to maximise the efficiency and effectiveness of AF treatment. Integrated care pathways provide an outline of anticipated multidisciplinary care and associated timeframes, for patients with a specific condition/set of symptoms, to enhance outcomes. ${ }^{31}$ The development of an integrated pathway requires a shared vision among multiple stakeholders across the healthcare sector, the transfer of AF treatment from the hospital to the community and using potential benefits from technology to improve data collection, monitoring and patient outcomes. As such, the participants identified stakeholder integration as an important preliminary step in the development of integrated care systems for AF treatment. Participants noted that this vision requires a shared message to be adopted 
by multiple stakeholders across the healthcare system at national, regional and local levels (see table 2).

\section{Location of care providers}

There was a general consensus among the participants that a redesign of the medical care pathway was required to maximise the efficiency and effectiveness of AF treatment. The majority of participants suggested moving AF treatment out of the hospital and into the community pharmacy. Participants noted that AF treatment requires multiple healthcare professionals including doctors, pharmacists and nurses. However, there was some disagreement regarding the redesign of the system with some participants pointing to dangers of transferring $\mathrm{AF}$ treatment from secondary to primary care. The redesign of the AF medical care pathway is far from straightforward and requires careful design and implementation. The participants identified challenges relating to scarcity of resources, defining and conceptualising the boundaries between primary and secondary care, and the linkages between the two. Furthermore, some participants highlighted the potential negative impacts of such changes from a business/financial perspective for general practice. In a redesigned system though, using mainly NOACs, the balance ought to be skewed much more towards primary care-but not to the exclusion of secondary care.

\section{Preventative healthcare}

Participants emphasised the need to increase preventative health measures through screening for early detection of potential health issues which increases the likelihood of successful AF treatment. One participant identified poor lifestyle choices and changes in population demographics as key factors influencing the need for preventative healthcare. Another participant highlighted the relatively small portion of the population over the age of 65 that have access to AF screening, which they identified as a useful future metric.

\section{Data-driven environment}

There was general consensus among participants that management of $\mathrm{AF}$ in the future needs to be driven by data collection to facilitate treatment plans tailored to specific patient needs, while remaining evidence based. One participant identified the potential of integrated data-driven systems for reducing the burden on both healthcare practitioners and patients during the treatment process. Participants highlighted numerous benefits of integrated data systems including increased patient empowerment, reductions in fear of litigation and more efficient and effective decision-making.

\section{Impact of technological advancement}

Participants also identified the potential for advancements in technology, now that patients have smart watches and phones, to contribute to improvements in both clinician and patient empowerment. The potential benefits of technology at a macro level include increased accessibility, improvements in efficiency and increased diagnosis. Considerable growth in the number of diagnoses resulting from technological advancements is anticipated. Furthermore, a participant suggested a significant increase in the number of people prescribed anticoagulants, with 9 out of every 10 expected to be prescribed NOACs, rather than warfarin. In addition, participants highlighted the potential for advancements in technology to facilitate patients taking ownership over their own health, transforming the doctor-patient relationship and providing patients with management capabilities over their own treatment (see table 2).

\section{Theme 2. Potential barriers}

\section{Anticoagulant issues}

Both clinicians and academics highlighted the need to take a more holistic perspective of the cost associated with warfarin. Specifically, they asserted the need to consider both short-term and long-term cost implications for the Irish healthcare system. Despite the perceived short-term savings, participants suggested that the cumulative direct and indirect costs of warfarin often outweigh that of alternatives such as NOACs over a longer period of time. For instance, one participant pointed towards how some clinicians are unaware of the differences in monitoring costs between warfarin and NOACs.

The participants also discussed how adverse effects from warfarin are particularly common among elderly patients who, as it happens, also account for the largest patient group who are prescribed the drug. One participant spoke of the personal impact of warfarin's adverse effects on quality of life and provided emotional accounts of the gastric bleeds that regularly occur. The participant felt that 'anything would be better' than warfarin and spoke on behalf of users of the drug by noting that clinicians often do not have an appreciation of the day-to-day suffering experienced by patients who are using the drug, and if they did it may influence their prescribing behaviour (see table 3).

\section{Effective treatment}

At an institutional level, resource availability in both primary and secondary care settings was identified as a key barrier to the effective treatment of anticoagulants. One participant noted how shortfalls in nursing staff who are treating patients with $\mathrm{AF}$ within a primary care setting has placed excessive pressures on clinicians in primary care and hospitals, leading to them treating a larger number of patients. Given the numerous responsibilities that both GPs and clinicians must cater for on a daily basis, time constraints were identified as an institutional barrier for effective treatment. Some participants emphasised how this sometimes impeded their ability to deliver effective treatment using anticoagulants. Other participants responded in agreement, signalling the lack of slack in schedules to allow for quicker GP referral and more time per patient appointment.

The opportunities available via digital solutions, such as wearable health trackers, which could allow a growing 
Table 3 Potential barriers

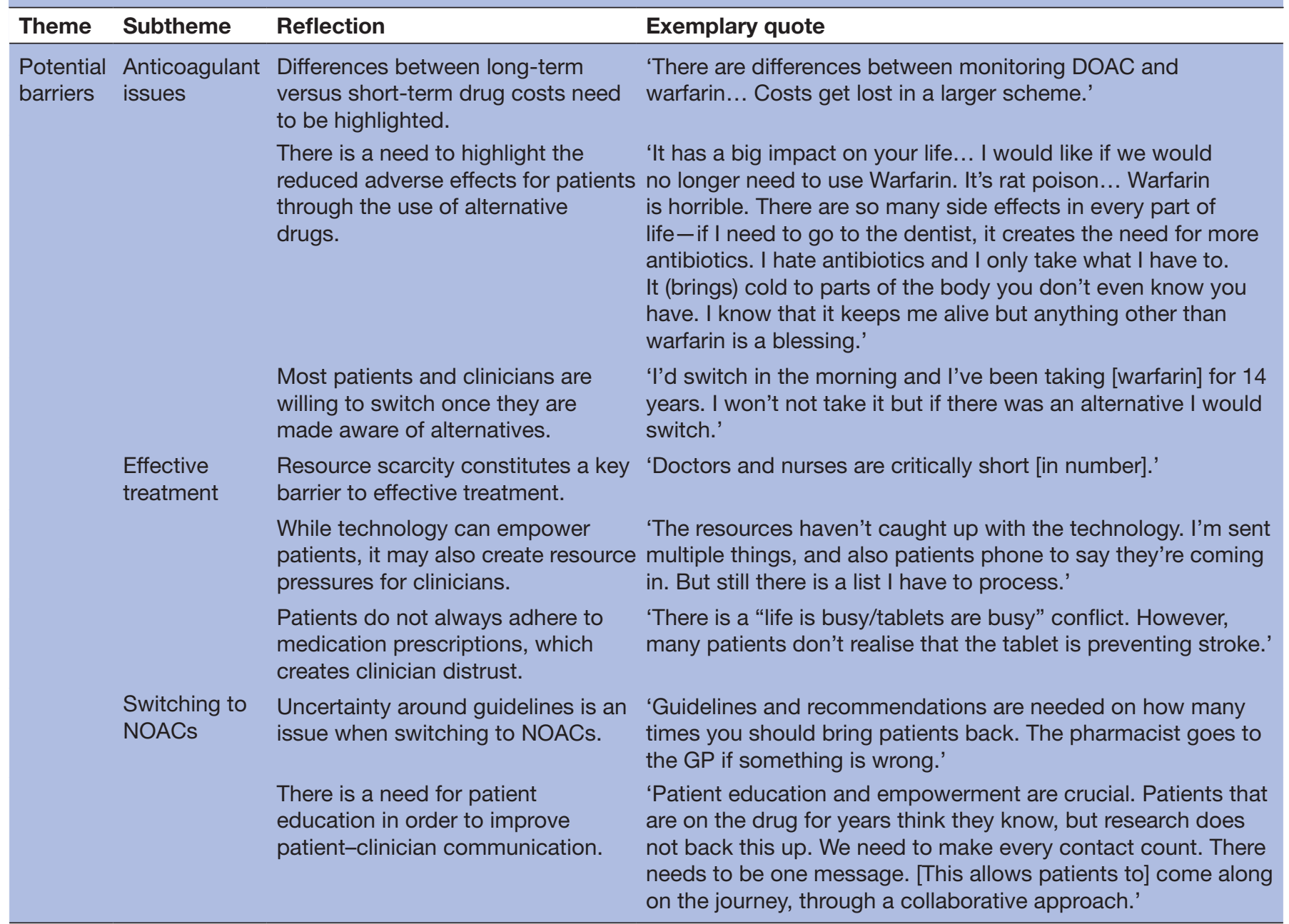

DOAC, direct oral anticoagulant; GP, general practitioner; NOAC, new oral anticoagulant.

number of patients to monitor their own well-being, were met with enthusiasm among the participants. Even the advantages of basic communication media, such as email, to enable patients to interact with clinicians more easily, were cited. However, some participants were more ambivalent towards the empowerment that information technology (IT) provides patients, as they were concerned about the extra demands that these technologies place on the workloads of busy doctors and clinics. As an example, it was noted how new resource pressures were being created by technology, such as wearable trackers and email, as they increase the accessibility of clinicians to patients and patients to clinicians. They spoke of how the rising volume of communication has created a sense of helplessness among clinicians which inevitably means that some critical messages are being inadvertently ignored.

Patient non-adherence, due to forgetting to take their medicines and/or failing to follow instructions, was identified as barrier to effective treatment. However, one participant warned against the introduction of 'big brother' surveillance tactics to ensure medication adherence among patients, citing it as intrusive. Instead, discussions centred on addressing asymmetries of information between clinicians and patients. Other participants spoke of clinicians' reliance on paper-based records and the lack of systems integration between primary and secondary care. Clinicians require patients to disclose all relevant information during appointments to address incomplete patient records. However, clinicians felt that patients' forgetfulness and piecemeal documentation of medical information could lead to lawsuits arising from medical errors (see table 3 ).

\section{Switching to NOACs}

One barrier to switching to NOACs was the clinician's lack of adherence to the guidelines for anticoagulant prescriptions. Participants discussed how the majority of respondents were not currently following all aspects of the proposed guidelines around anticoagulant prescription, despite the high volume of prescriptions. Participants also noted how ambiguities inherent in the guidelines for anticoagulant prescriptions were inhibiting a switch to NOACs. For instance, guidelines mention both 3-month and 6-month review intervals. Such ambiguity could be 
an inhibitor to change. The participants called for new guidelines which would address these uncertainties and increase clinician confidence when switching to NOACs. Additionally, they spoke about how clinicians' past experiences of prescribing warfarin should be considered when trying to promote a switch to NOACs. GPs who have experienced negative patient outcomes from warfarin may be more likely to switch to NOACs.

Questions were also raised about how clinicians currently triage patients to determine whether the prescribing of anticoagulant drugs was appropriate. Given the impact that drugs such as warfarin can have on a patient's quality of life, clinicians found it important to approach this prescribing decision with due care. Participants pointed to the need for doctors and patients to be informed of the economical and clinical grounds supporting the use of NOACs. In particular, they pointed towards the empowering nature of education for patients, suggesting that an increase in patients' medication literacy can enable them to become a collaborator in their own healthcare. The delivery of a consistent and reinforced message around patient care was identified as crucial (see table 3 ).

\section{DISCUSSION}

The multistakeholder focus group identified that enhanced patient empowerment, more effective use of technology and developing system-based medical care pathways would provide improved supports for AF management. Nevertheless, there are challenges in providing these (including cost and access issues) with the doctor-patient relationship and education being imperative to its effectiveness. While consensus for developing evidence-based medical care pathways to maximise efficiency and effectiveness of AF treatment was evident, it would require a shared vision between stakeholders for integrated care. Divergence on where the services should be located was found.

Clinicians also emphasised the need to include preventative healthcare in the dedicated medical care pathway. While the benefits of embracing technological advances for clinicians and patients are anticipated (and still being investigated), there is a caveat that it can increase pressure on already stretched resources; coupled with institutional barriers (including scarce resources), barriers arising from the complex nature of anticoagulation for patients with $\mathrm{AF}$, including: the unpredictable nature of warfarin; hidden costs associated with monitoring; adverse clinical effects; different patient cohorts (including those prescribed anticoagulant for the first time vs those switching from warfarin to a NOAC); non-adherence concerns and undesirable impacts on patients' daily lives.

This study reflects on data collected via one multistakeholder focus group that facilitated face-to-face dialogue between multiple stakeholders including clinicians (general practice, cardiology, geriatrics and pharmacology), a patient and academics (healthcare and health economics) using an experienced facilitator. The World
Café method facilitated a constructive dialogue, featuring equitable contribution and participation among participants, generating collective knowledge sharing. A wide range of qualitative evidence generation and analysis techniques have been employed in the literature examining anticoagulation and NOACs for AF management, including individual or focus group semistructured interviews, ${ }^{32-36}$ or combinations of observation and interviews. ${ }^{36} 37$ These previous studies mainly focused on a single stakeholder group, predominately patients. When multistakeholders were involved, focus groups and individual interviews were employed ${ }^{36}$ In this study, the focus group facilitated discourse around diverse contributions, ${ }^{38}{ }^{39}$ whereby participants were able to reflect on their own interpretations and refine their thinking. ${ }^{38}$ This provided an opportunity for collaborative discussion among the stakeholders while connecting diverse experiences on identifying future priorities for health service delivery to patients with AF in Ireland.

We also acknowledge weaknesses in the approach. First, in contrast to semistructured interviews, focus groups may limit the ability of individuals to provide detailed accounts of their personal views and perspectives on a subject matter, as the discussion time is shared among all the participants present. Second, the analysis is subject to potential biases owing to sample selection. While the organisers issued invitations to a broad range of clinicians across specialties, hospital groups, patient organisations, patient groups and regulatory bodies $(n=28)$ uptake was low (32\%). As a result, the participants were from a similar geographical location and this may result in selfselection bias. Furthermore, the multistakeholder focus group was centred at a macro level to start the conversation about the future vision for managing patients with AF; deeper exploration of the themes identified and beyond, with greater stakeholder participation, is warranted via further research to inform future policy and practice. The World Café approach was chosen to reflect this also. This approach fosters open, intimate and authentic conversation in small groups, ${ }^{4041}$ as was the case here. As previous research demonstrates it can be used to explore the impact of existing and emerging issues, for example, in the case of pharmacy practices in Ireland, ${ }^{42}$ and to demonstrate how a small number of user representatives (i.e., patient personas) can support consideration of larger, more diverse populations. ${ }^{43}$

This study explores some key challenges facing patients with $\mathrm{AF}$ and the healthcare professionals prescribing and managing their treatment, which were largely consistent with those identified previously. ${ }^{6} 256$ However, multistakeholder focus groups offer depth by providing multiple individual perspectives by giving them a voice. While anticoagulation therapy for patients with AF using NOACs is widely adopted and is diffusing into routine practice significant operationalisation issues and barriers to effective treatment/management persist. The reflections presented in this study can be used to inform the next phase of designing clinical and policy initiatives to 
generate a fit-for-purpose, evidence-based treatment pathway(s). Specifically, findings support previous recommendations ${ }^{44}$ for a shared decision-making approach which can act as a mechanism for enhancing the patient-centred nature of AF management. Furthermore, increased patient involvement in the development of educational materials and other patient resources as advocated by Clarkesmith $e t a l^{5}$ is desirable.

The multistakeholder focus group confirmed and reinforced the need for better direction and clearer requirements for patients with $\mathrm{AF}$ receiving anticoagulation in Ireland. Findings suggest a desire for a shared decisionmaking approach, treatment pathways, greater patient empowerment and enhanced used of IT; although further investigations on their feasibility and operationalisation are warranted. The observations presented here are a catalyst for future discussion and research.

Contributors $\mathrm{AM}, \mathrm{AK}$ and $\mathrm{CB}$ made substantial contributions to the conception and design of the work. POR made substantial contributions to design of the work. AM, SB and SMC made substantial contributions to analysis, interpretation of data and drafting the manuscript. All authors contributed to revising the work critically for important intellectual content and approved the final version.

Funding This work was supported by the College of Business and Law Strategic Research Fund at University College Cork.

Competing interests None declared.

Patient and public involvement Patients and/or the public were involved in the design, or conduct, or reporting, or dissemination plans of this research. Refer to the Methods section for further details.

\section{Patient consent for publication Not required.}

Ethics approval Due to the anonymised nature of the evidence presented in the study, this research carries little to no risk to participants. No ethical approval was sought to hold the World Café. After the event, we emailed participants to make them aware that we were going to write up a reflection of the event for publication. The writing does not identify or compare the contributions of individual attendees. The right of all participants to confidentiality was maintained, including secure data storage.

Provenance and peer review Not commissioned; externally peer reviewed.

Data availability statement Data are available upon reasonable request from the corresponding author. ORCID 0000-0003-3062-0692.

Open access This is an open access article distributed in accordance with the Creative Commons Attribution Non Commercial (CC BY-NC 4.0) license, which permits others to distribute, remix, adapt, build upon this work non-commercially, and license their derivative works on different terms, provided the original work is properly cited, appropriate credit is given, any changes made indicated, and the use is non-commercial. See: http://creativecommons.org/licenses/by-nc/4.0/.

\section{ORCID iDs}

Aileen Murphy http://orcid.org/0000-0003-3062-0692

Ann Kirby http://orcid.org/0000-0002-9043-5483

\section{REFERENCES}

1 Hart RG, Benavente O, McBride R, et al. Antithrombotic therapy to prevent stroke in patients with atrial fibrillation: a meta-analysis. Ann Intern Med 1999;131:492-501.

2 Ruff CT, Giugliano RP, Braunwald E, et al. Comparison of the efficacy and safety of new oral anticoagulants with warfarin in patients with atrial fibrillation: a meta-analysis of randomised trials. Lancet 2014;383:955-62.

3 Lacoin L, Lumley M, Ridha E, et al. Evolving landscape of stroke prevention in atrial fibrillation within the UK between 2012 and 2016: a cross-sectional analysis study using CPRD. BMJ Open 2017;7:e015363.
4 Gadsbøll K, Staerk L, Fosbøl EL, et al. Increased use of oral anticoagulants in patients with atrial fibrillation: temporal trends from 2005 to 2015 in Denmark. Eur Heart J 2017;38:ehw658.

5 Rodríguez-Bernal CL, Hurtado I, García-Sempere A, et al. Oral anticoagulants initiation in patients with atrial fibrillation: real-world data from a population-based cohort. Front Pharmacol 2017;8:63.

6 Afzal SK, Hasan SS, Babar ZU-D. A systematic review of patientreported outcomes associated with the use of direct-acting oral anticoagulants. Br J Clin Pharmacol 2019;85:2652-67.

7 Broderick JP, Bonomo JB, Kissela BM, et al. Withdrawal of antithrombotic agents and its impact on ischemic stroke occurrence. Stroke 2011;42:2509-14.

8 Fang MC, Go AS, Chang Y, et al. Warfarin discontinuation after starting warfarin for atrial fibrillation. Circ Cardiovasc Qual Outcomes 2010;3:624-31.

9 Medicines Management Programe, Health Services Executive. Oral anticoagulants for stroke prevention in non-valvular atrial fibrillation. Dublin, Ireland, 2019.

10 Health Services Executive. Primary care reimbursement scheme: statistical analysis of claims and payments. Dublin, Ireland, 2017.

11 Barry M, Clarke S, Geraghty N. The uptake of non-vitamin K oral anticoagulants in Ireland: balancing cost-effectiveness analysis and budget impact. Value in Health 2016;19:A57.

12 Health Services Executive. Primary care reimbursement scheme: statistical analysis of claims and payments. Dublin, Ireland, 2014.

13 Dobesh PP, Fanikos J. Direct oral anticoagulants for the prevention of stroke in patients with nonvalvular atrial fibrillation: understanding differences and similarities. Drugs 2015;75:1627-44.

14 Walsh C, Murphy A, Kirby A, et al. Retrospective costing of warfarin. Ir Med J 2014;107:133-5.

15 Sharma M, Cornelius VR, Patel JP, et al. Efficacy and harms of direct oral anticoagulants in the elderly for stroke prevention in atrial fibrillation and secondary prevention of venous thromboembolism: systematic review and meta-analysis. Circulation 2015;132:194-204.

16 Heidbuchel H, Berti D, Campos M, et al. Implementation of nonvitamin $\mathrm{K}$ antagonist oral anticoagulants in daily practice: the need for comprehensive education for professionals and patients. Thromb J 2015;13:22.

17 European Heart Rhythm Association, European Association for Cardio-Thoracic Surgery, Camm AJ, et al. Guidelines for the management of atrial fibrillation: the task force for the management of atrial fibrillation of the European Society of cardiology (ESC). Eur Heart J 2010;31:2369-429.

18 January CT, Wann LS, Alpert JS, et al. 2014 AHA/ACC/HRS guideline for the management of patients with atrial fibrillation: executive summary: a report of the American college of cardiology/American heart association task force on practice guidelines and the heart rhythm society. J Am Coll Cardiol 2014;64:2246-80.

19 Kirchhof $\mathrm{P}$, Kotecha D, Ahlsson A, et al. ESC guidelines for the management of atrial fibrillation developed in collaboration with EACTS. Revista española de Cardiologia 2017;70:1-84.

20 Kirby A, Murphy A, Bradley C. Multi-disciplinary decision making in general practice: a case study of switching between oral anticoagulants. J Health Organ Manag 2018;32:146-56.

21 Murphy A, Kirby A, Bradley C. Knowledge is power: genera practitioners prescribing of new oral anticoagulants in Ireland. BMC Res Notes 2018;11:478.

22 Kirby A, Murphy A, Bradley C. New oral Anaticoagulant prescribing decisions amongst general practitioners: handle with care. J Health Econ Outcomes Res 2017;5:55-64.

23 Murphy A, Kirby A, Bradley C. Monitoring of atrial fibrillation in primary care patients prescribed direct oral anticoagulants for stroke prevention. Ir J Med Sci 2020;189:961-6.

24 Hao Y, Liu J, Smith SC, et al. Rationale and design of the improving care for cardiovascular disease in China (CCC) project: a national registry to improve management of atrial fibrillation. BMJ Open 2018;8:e020968.

25 Generalova D, Cunningham S, Leslie SJ, et al. A systematic review of clinicians' views and experiences of direct-acting oral anticoagulants in the management of nonvalvular atrial fibrillation. $\mathrm{Br} \mathrm{J}$ Clin Pharmacol 2018;84:2692-703.

26 Carlsen B, Glenton C, Pope C. Thou shalt versus thou shalt not: a meta-synthesis of GPs' attitudes to clinical practice guidelines. $\mathrm{Br} \mathrm{J}$ Gen Pract 2007;57:971-8.

27 Fouché C, Light G. An invitation to dialogue: 'the world café'in social work research. Qual Social Work 2011;10:28-48.

28 O'Brien BC, Harris IB, Beckman TJ, et al. Standards for reporting qualitative research: a synthesis of recommendations. Acad Med 2014;89:1245-51.

29 Braun V, Clarke V. Using thematic analysis in psychology. Qual Res Psychol 2006;3:77-101. 
$30 \mathrm{Ha}$ JF, Longnecker N. Doctor-patient communication: a review. Ochsner J 2010;10:38-43.

31 Darker C. Integrated healthcare in Ireland-a critical analysis and a way forward. Adelaide Health Foundation 2014.

32 Thrysoee L, Birkelund L, Birkelund R. A qualitative study of clinical decision-making in a multidisciplinary outpatient clinic for patients with atrial fibrillation - from the patient's perspective. Eur J Pers Cent Healthc 2018;6:610-20.

33 Gillespie C, Rose AJ, Petrakis BA, et al. Qualitative study of patient experiences of responsibility in warfarin therapy. Am J Health Syst Pharm 2018;75:1798-804

34 Böttger B, Thate-Waschke I-M, Bauersachs R, et al. Preferences for anticoagulation therapy in atrial fibrillation: the patients' view. J Thromb Thrombolysis 2015;40:406-15.

35 Clarkesmith DE, Lip GYH, Lane DA. Patients' experiences of atrial fibrillation and non-vitamin K antagonist oral anticoagulants (NOACs), and their educational needs: a qualitative study. Thromb Res 2017:153:19-27.

36 Borg Xuereb C, Shaw RL, Lane DA. Patients' and health professionals' views and experiences of atrial fibrillation and oralanticoagulant therapy: a qualitative meta-synthesis. Patient Educ Couns 2012;88:330-7.

37 Thrysoee L, Strömberg A, Brandes A, et al. Management of newly diagnosed atrial fibrillation in an outpatient clinic setting-patient's perspectives and experiences. J Clin Nurs 2018;27:601-11.
38 Ritchie Jet al. Qualitative research practice: a guide for social science students and researchers. Sage, 2013.

39 Krueger RA, Casey MA. Focus groups: a practical guide for applied research. Sage, 2014.

40 Brown J. A resource guide for the world café. In: A resource guide for hosting conversations that matter at the world café. World Café Community, Whole Systems Associates, 2002.

41 User Participation. World cafe - description, 2017. Available: https://www.user-participation.eu/planning-the-process/step5-participatory-methods/planning-the-future-visions-strategiesprojects/world-cafe

42 Kavanagh ON, Moriarty F, Bradley C, et al. More than coffee - a world café to explore enablers of pharmacy practice research. Int J Pharm Pract 2020

43 Putnam C, Rose E, Johnson EJ, et al. Adapting user-centered design methods to design for diverse populations. Inform Tech Int Develop 2009;5.

44 Seaburg L, Hess EP, Coylewright M, et al. Shared decision making in atrial fibrillation: where we are and where we should be going. Circulation 2014;129:704-10.

45 Berends L, Johnston J. Using multiple coders to enhance qualitative analysis: the case of interviews with consumers of drug treatment. Addict Res Theory 2005;13:373-81. 